\title{
Reldesemtiv in Patients with Spinal Muscular Atrophy: a Phase 2 Hypothesis-Generating Study
}

\author{
Stacy A. Rudnicki ${ }^{1}$. Jinsy A. Andrews ${ }^{1,2} \cdot$ Tina Duong $^{3} \cdot$ Bettina M. Cockroft ${ }^{1,4} \cdot$ Fady I. Malik $^{1} \cdot$ Lisa Meng $^{1}$. \\ Jenny Wei ${ }^{1}$ • Andrew A. Wolff ${ }^{1}$ • Angela Genge ${ }^{5}$ - Nicholas E. Johnson ${ }^{6,7}$. Carolina Tesi-Rocha ${ }^{3}$ - Anne M. Connolly ${ }^{8,9}$. \\ Basil T. Darras ${ }^{10} \cdot$ Kevin Felice $^{11} \cdot$ Richard S. Finkel $^{12,13} \cdot$ Perry B. Shieh $^{14} \cdot$ Jean K. Mah ${ }^{15}$ • Jeffrey Statland ${ }^{16}$. \\ Craig Campbell ${ }^{17}$ - Ali A. Habib ${ }^{18} \cdot$ Nancy L. Kuntz $^{19} \cdot$ Maryam Oskoui $^{20} \cdot$ John W. Day $^{3}$ (I)
}

Accepted: 30 December 2020

(C) The Author(s) 2021, corrected publication 2021

\begin{abstract}
This phase 2, double-blind, placebo-controlled, hypothesis-generating study evaluated the effects of oral reldesemtiv, a fast skeletal muscle troponin activator, in patients with spinal muscular atrophy (SMA). Patients $\geq 12$ years of age with type II, III, or IV SMA were randomized into 2 sequential, ascending reldesemtiv dosing cohorts (cohort 1: $150 \mathrm{mg}$ bid or placebo [2:1]; cohort 2: $450 \mathrm{mg}$ bid or placebo [2:1]). The primary objective was to determine potential pharmacodynamic effects of reldesemtiv on 8 outcome measures in SMA, including 6-minute walk distance (6MWD) and maximum expiratory pressure (MEP). Changes from baseline to weeks 4 and 8 were determined. Pharmacokinetics and safety were also evaluated. Patients were randomized to reldesemtiv $150 \mathrm{mg}, 450 \mathrm{mg}$, or placebo $(24,20$, and 26 , respectively). The change from baseline in $6 \mathrm{MWD}$ was greater for reldesemtiv $450 \mathrm{mg}$ than for placebo at weeks 4 and 8 (least squares [LS] mean difference, $35.6 \mathrm{~m}[p=0.0037]$ and $24.9 \mathrm{~m}[p=$ 0.058], respectively). Changes from baseline in MEP at week 8 on reldesemtiv 150 and $450 \mathrm{mg}$ were significantly greater than those on placebo (LS mean differences, $11.7[p=0.038]$ and $13.2 \mathrm{~cm} \mathrm{H}_{2} \mathrm{O}[p=0.03]$, respectively). For 6MWD and MEP, significant changes from placebo were seen in the highest reldesemtiv peak plasma concentration quartile $\left(C_{\max }>3.29 \mu \mathrm{g} / \mathrm{mL}\right.$; LS mean differences, $43.3 \mathrm{~m}[p=0.010]$ and $28.8 \mathrm{~cm} \mathrm{H}_{2} \mathrm{O}[p=0.0002]$, respectively). Both dose levels of reldesemtiv were well tolerated. Results suggest reldesemtiv may offer clinical benefit and support evaluation in larger SMA patient populations.
\end{abstract}

Key Words Reldesemtiv $\cdot$ spinal muscular atrophy clinical trial $\cdot$ pharmacodynamics $\cdot$ pharmacokinetics $\cdot$ six-minute walk test

John W. Day

jwday@stanford.edu

Cytokinetics, Incorporated, South San Francisco, CA, USA

Columbia University, New York, NY, USA

Stanford University, Stanford, CA, USA

4 Sangamo Therapeutics, Brisbane, CA, USA

5 Montreal Neurological Institute, Montreal, QC, Canada

6 Virginia Commonwealth University, Richmond, VA, USA

7 University of Utah, Salt Lake City, UT, USA

8 Nationwide Children's Hospital, Columbus, OH, USA

9 Washington University, St Louis, MO, USA

10 Boston Children's Hospital and Harvard Medical School, Boston, MA, USA

11 Hospital for Special Care, New Britain, CT, USA
12 Nemours Children's Hospital, Orlando, FL, USA

13 St. Jude Children's Research Hospital, Memphis, TN, USA

14 University of California, Los Angeles, Los Angeles, CA, USA

15 University of Calgary, Alberta Children's Hospital, Calgary, AB, Canada

16 University of Kansas, Lawrence, KS, USA

17 Department of Pediatrics, Epidemiology and Clinical Neurological Sciences, University of Western Ontario, London Health Sciences Centre, London, ON, Canada

18 University of California, Irvine, Orange, CA, USA

19 Ann \& Robert H. Lurie Children's Hospital of Chicago, Chicago, IL, USA

20 McGill University Health Centre Research Institute, Montreal, QC, Canada 


\section{Introduction}

Spinal muscular atrophy (SMA) is a genetic neuromuscular disease in which reduced amounts of functional survival motor neuron (SMN) protein result in progressive muscle weakness and atrophy, leading to various degrees of functional motor impairment [1]. Analyses of markers of muscle involvement, including contractile and regulatory proteins, suggest a delay in muscle maturation in samples from patients with SMA compared to controls [2, 3]. Magnetic resonance imaging of muscle in children and adults aged 2 to 45 years with SMA type II and III showed differences with varying degrees of proximal to distal gradient, but found some muscle groups were always spared and muscles involved demonstrated atrophy in both SMA types [4].

Although SMA has historically been classified based on age of onset and highest level of motor function achieved [1], in the advent of recently approved therapies, this classification system has become less relevant. All three recently approved SMA course-modifying treatments increase motor neuron SMN protein content. Nusinersen, an antisense oligonucleotide drug that increases SMN production by altering $S M N 2$ splicing $[5,6]$, was the first approved medication for the specific treatment of SMA. The beneficial effects of nusinersen in infants and children are well substantiated [5-8], but currently there are limited data available from older patients; findings for nusinersen in adults are limited to observational studies rather than controlled clinical trials $[9,10]$. The gene therapy onasemnogene abeparvovec-xioi is effective in infants and recently gained approval by the US Food and Drug Administration for patients $<2$ years of age with SMA [11, 12]. In addition, risdiplam, a small molecule $S M N 2$ splicing modifier, is also now approved to treat patients 2 months and older with SMA, and has been studied in a randomized, double-blind, placebo-controlled study in patients up to the age of $25[13,14]$. Even after treatment with these new therapies, many very young SMA patients fail to meet age-specific motor milestones, and treatment later in the course of disease results in even less dramatic benefits.

Therefore, there continue to be unmet medical needs despite these dramatic advances, particularly regarding persistent weakness, impaired endurance, and fatigue [8, 12]. As new emerging treatments for SMA impact the development of motor milestones, and as treatment before manifestation of symptoms may be possible through newborn screening, the clinical features of SMA are likely to slowly evolve. Other features such as $S M N 2$ copy number, and age of onset of signs and symptoms may also impact clinical course $[15,16]$, but even as the clinical landscape of SMA evolves, the vast majority of patients will continue to experience weakness and fatigue.

Reldesemtiv (CK-2127107) is being developed to improve skeletal muscle function for disease states involving muscle weakness or fatigue; it selectively binds to the fast skeletal troponin complex and sensitizes it to calcium [17]. In a double-blind, randomized, placebo-controlled, phase 1 clinical study in healthy participants, fibular nerve stimulation at sub-tetanic frequencies resulted in significantly increased placebo-corrected changes in the force generated by the tibialis anterior muscle in a dose-, concentration-, and frequency-dependent manner following reldesemtiv treatment. In this and 2 additional double-blind, randomized, placebo-controlled, phase 1 studies, reldesemtiv was well tolerated at singledose levels from 30 to $4000 \mathrm{mg}$ and multiple doses of 300 and $500 \mathrm{mg}$ twice daily (bid) [18]. Adverse events (AEs) observed in $\geq 10 \%$ of patients in at least one of the studies included headache, dizziness, nausea, and asthenopia (eye strain); all AEs were mild or moderate in severity. No meaningful differences in pharmacokinetic (PK) parameters were found between young and elderly volunteers.

We conducted a hypothesis-generating, phase 2 study with no pre-specified primary outcome measure that tested a number of pharmacodynamic (PD) outcomes. Two oral dose levels (150 and $450 \mathrm{mg}$ bid) of reldesemtiv were evaluated in patients with SMA. Secondary objectives were to evaluate the safety and tolerability of reldesemtiv as well as its PK properties.

\section{Methods}

\section{Study Design}

The study was a phase 2, double-blind, randomized, placebocontrolled, multiple-dose investigation of reldesemtiv in 2 sequential ascending dose cohorts of patients with SMA (ClinicalTrials.gov identifier NCT02644668), conducted from December 2015 through May 2018 at 18 centers in Canada and the USA. The study received approval from institutional review boards before commencing, and was conducted in compliance with good clinical practice and the Declaration of Helsinki; written informed consent was obtained from patients $\geq 18$ years of age, and parental permission and child assent were obtained for those $<18$ years of age. Patients were randomized via an interactive web response system to receive reldesemtiv $150 \mathrm{mg}$ bid or placebo $(2: 1$; cohort 1$)$, or reldesemtiv $450 \mathrm{mg}$ bid or placebo (2:1; cohort 2$)$, stratified by ambulatory status. The study drug was constituted with water at the site; the suspension was given to the patient for oral administration $(9 \mathrm{~mL})$ bid, approximately every $12 \mathrm{~h}$ after a $\geq 3$-h fast, with a 1-h fast following dosing, for a total of 8 weeks.

\section{Study Participants}

Patients eligible for enrollment had genetically confirmed diagnosis of type II, III, or IV SMA and were $\geq 12$ years of age. Ambulatory patients, after independently achieving a standing position, were required to complete at least 1 lap $(\geq 50 \mathrm{~m})$ in 
the 6-minute walk test (6MWT) without assistance. Nonambulatory patients needed to be able to tolerate an upright supported sitting position continuously for $3 \mathrm{~h}$, and required a wheelchair for mobility needs, though they may have been able to stand or walk less than $50 \mathrm{~m}$ without assistance in $6 \mathrm{~min}$. Patients were also required to have forced vital capacity (FVC) $>20 \%$ predicted, Hammersmith Functional Motor Scale Expanded (HFMSE) score $\geq 10$ and $\leq 54$, and contracture of elbow flexion $\leq 90$ degrees. Patients must have been able to swallow an oral suspension and were expected to be able to continue to do so for the duration of the study. Prior or concomitant treatment with nusinersen was not allowed.

\section{Outcome Measures}

Outcome measures were assessed at screening, day 1, at the end of weeks 1,2, 4, and 8, and at follow-up (4 weeks after the last dose) for all except timed up and go (TUG) and 6MWT, which were assessed at screening, day 1 , at the end of weeks 4 and 8, and at follow-up. The Spinal Muscular Atrophy-Health Index (SMA-HI) was completed on day 1 and at the end of week 8 in cohort 2 only. All clinical measures were standardized with certified clinical evaluators who underwent appropriate training to ensure consistency of measures across all sites and visits throughout the study.

Pulmonary function was assessed via FVC, as well as maximum inspiratory pressure (MIP) and maximum expiratory pressure (MEP), measured using calibrated spirometers by Micro Direct, Inc., Lewiston, ME (FVC: MicroLab Spirometer MK8; MIP and MEP: MicroRPM). Isometric muscle strength was assessed bilaterally using a make test, in which the examiner holds the dynamometer in a set position as the patient pushes against it, for 3 muscle groups (elbow flexion, knee flexion, and shoulder abduction) with a MicroFET2 handheld dynamometer (HHD, Hoggan Scientific, LLC, Salt Lake City, UT). The maximum muscle strength of 2 measurements was reported as percent change from baseline, with imputed muscle strength set to missing if the baseline value was 0 . The mega-score, a composite score for strength across the 3 muscle groups, was calculated as the mean of transformed muscle strength scores. The HFMSE was used to evaluate functional mobility with a scale score ranging from 0 to 66, with higher scores reflecting better function [19]. The revised upper limb module (RULM) was designed to be used in conjunction with the HFMSE; it tests upper limb function based on reachable workspaces from upper (shoulder), middle (elbow), and distal (wrist and hand) regions of the upper limb with a range of scoring from 0 to 44 , with higher scores reflecting greater function [20].

The 6MWT, performed in ambulatory patients, measured the distance a patient walked in $6 \mathrm{~min}$ (6MWD) in order to assess functional endurance capacity and mobility; fatigue was measured by the difference in distance walked between the first and last minutes [21]. To assess mobility, balance, and walking ability, the TUG, performed in ambulatory patients, measured the time for a patient to rise from a chair, traverse $3 \mathrm{~m}$, turn around, return to the chair, and sit down [22]. Patient-reported SMA burden was measured using the SMA-HI questionnaire, with higher scores reflecting greater burden of disease; this was performed only in cohort 2 given the timing of when the questionnaire was fully developed [23]. Safety was assessed by monitoring AEs, coded using the Medical Dictionary for Regulatory Activities (MedDRA), version 18.0, clinical laboratory findings, and electrocardiogram intervals.

For PK endpoints, blood samples for determination of plasma concentrations of reldesemtiv were collected prior to dosing on day 1 and at the ends of weeks 1,2,4, and 8. Concentrations were determined by a validated solid-phase extraction method using high-performance liquid chromatography followed by tandem mass spectrometric detection.

\section{Statistical Analysis}

The safety population consisted of all patients who received $\geq 1$ dose of study drug, whereas the PD population included patients in the safety population with $\geq 1$ post-baseline endpoint assessment, and the PK population included those in the safety population with $\geq 1$ evaluable PK level. Baseline characteristics and safety data were summarized descriptively overall and by treatment, dose level, and ambulatory status in the safety population.

For dose-response PD effects, the change from baseline in a continuous endpoint was analyzed by repeated measures mixed effect models that accounted for within-patient correlation with an unstructured covariance matrix or compound symmetry when an unstructured covariance matrix could not converge. The covariates included dose level, visit, interaction between dose level and visit, ambulatory status, and the baseline value of the variable being analyzed (except for muscle strength mega-score, for which the score itself represents a percent change from baseline). Ambulatory status was removed from the model for subgroup analyses by ambulatory status. Important baseline characteristics (including age, gender, and age of disease onset) were also examined and included in the model.

The slope of change from baseline for continuous endpoints was analyzed by a mixed effect model with no intercept, and included dose level, days from the first dose of study treatment as a random covariate, interaction of dose level-bydays from the first dose of study treatment, ambulatory status, and baseline value of the variable being analyzed.

Maximum observed plasma concentration $\left(C_{\max }\right)$, predose plasma concentration $\left(C_{\text {trough }}\right)$, and area under the plasma concentration-time curve from 0 to $12 \mathrm{~h}\left(\mathrm{AUC}_{0-12}\right)$ were calculated based on the plasma concentrations of reldesemtiv using noncompartmental PK methods and were summarized descriptively. For concentration-response PK analyses, the change in continuous endpoints from baseline was analyzed by a mixed effect model that accounted for within-patient 
Table 1 Baseline demographics, disease characteristics, and pharmacodynamic measures

\begin{tabular}{|c|c|c|c|c|}
\hline & $\begin{array}{l}\text { Placebo } \\
(n=26)\end{array}$ & $\begin{array}{l}\text { Reldesemtiv } 150 \mathrm{mg} \\
\text { bid } \\
(n=24)\end{array}$ & $\begin{array}{l}\text { Reldesemtiv } 450 \mathrm{mg} \\
\text { bid } \\
(n=20)\end{array}$ & $\begin{array}{l}\text { Overall } \\
(n=70)\end{array}$ \\
\hline Age, years, mean (SD) & $28.5(16.0)$ & $27.8(12.0)$ & $32.6(17.9)$ & $29.4(15.3)$ \\
\hline Age $<18$ years, $n(\%)$ & $8(30.8)$ & $7(29.2)$ & $5(25.0)$ & $20(28.6)$ \\
\hline Male, $n(\%)$ & $15(57.7)$ & $14(58.3)$ & $12(60.0)$ & $41(58.6)$ \\
\hline White, $n(\%)$ & $22(84.6)$ & $23(95.8)$ & $18(90.0)$ & $63(90.0)$ \\
\hline BMI, mean (SD) & $24.3(7.4)$ & $25.4(9.2)$ & $25.1(5.5)$ & $24.9(7.5)$ \\
\hline SMA type II, $n(\%)$ & $2(7.7)$ & $3(12.5)$ & $1(5.0)$ & $6(8.6)$ \\
\hline SMA type III, $n(\%)$ & $24(92.3)$ & $21(87.5)$ & $19(95.0)$ & $64(91.4)$ \\
\hline $\begin{array}{l}\text { Age at SMA onset, years, } \\
\text { mean (SD) }\end{array}$ & $3.8(4.6)$ & $7.8(6.9)$ & $8.1(9.4)$ & $6.4(7.2)$ \\
\hline Ambulatory, $n(\%)$ & $11(42.3)$ & $12(50.0)$ & $8(40.0)$ & $31(44.3)$ \\
\hline $\begin{array}{l}\% \text { predicted FVC, mean } \\
\text { (SD) }\end{array}$ & $84.4(22.4)$ & $83.1(22.0)$ & $85.9(21.2)$ & $84.4(21.7)$ \\
\hline $\mathrm{MEP}, \mathrm{cm} \mathrm{H}_{2} \mathrm{O}$, mean (SD) & $86.5(36.9)$ & $94.0(43.4)$ & $88.9(47.7)$ & $89.8(41.8)$ \\
\hline $\mathrm{MIP}, \mathrm{cm} \mathrm{H} \mathrm{H}_{2} \mathrm{O}$, mean $(\mathrm{SD})$ & $\begin{array}{r}-105.7 \\
(38.5)\end{array}$ & $-109.1(44.2)$ & $-101.0(43.2)$ & $\begin{array}{r}-105.6 \\
(41.3)\end{array}$ \\
\hline HFMSE score, mean (SD) & $30.6(16.6)$ & $36.0(17.2)$ & $30.4(16.3)$ & $32.4(16.7)$ \\
\hline $\begin{array}{l}\text { RULM total score, mean } \\
\text { (SD) }\end{array}$ & $31.0(8.7)$ & $34.8(7.9)$ & $33.7(8.0)$ & $33.1(8.3)$ \\
\hline TUG, s, mean (SD) & $21.5(11.0)$ & $15.7(6.5)$ & $22.8(16.1)$ & $19.2(10.3)$ \\
\hline 6MWD, m, mean (SD) & $\begin{array}{l}240.1 \\
\quad(111.8)\end{array}$ & $316.6(69.0)$ & $311.0(107.3)$ & $287.3(99.2)$ \\
\hline $\begin{array}{l}\text { SMA-HI total score, } \\
\text { mean }(\mathrm{SD})^{\mathrm{a}}\end{array}$ & $33.1(19.9)$ & NA & $39.8(17.1)$ & $37.5(18.1)$ \\
\hline
\end{tabular}

${ }^{\text {a }}$ SMA-HI was only performed in participants in cohort 2

$6 M W D$ 6-minute walking distance, $B M I$ body mass index, bid twice daily, FVC forced vital capacity, HFMS-E Hammersmith Functional Motor Score-Expanded, $M E P$ maximum expiratory pressure, $M I P$ maximum inspiratory pressure, $N A$ not assessed, $R U L M$ revised upper limb module, $S D$ standard deviation, SMA-HI Spinal Muscular Atrophy-Health Index, TUG timed up and go correlation with an unstructured covariance matrix. The covariates included PK parameter, visit, interaction between visit and the PK parameter, ambulatory status, and the baseline value of the variable being analyzed.

For model-based PD analyses, least squares (LS) mean, difference of LS means between reldesemtiv and placebo (combined from the 2 cohorts), their standard errors (SEs) and $95 \%$ confidence intervals (CIs), and 2-sided $p$ values were determined. Multiplicity was not addressed in this hypothesisgenerating study; all $p$ values of statistical significance are nominal.

\section{Results}

\section{Patient Disposition and Baseline Characteristics}

Seventy patients were randomized to placebo $(n=26)$, reldesemtiv $150 \mathrm{mg}$ bid $(n=24)$, or reldesemtiv $450 \mathrm{mg}$ bid $(n=20)$ (Supplemental Fig. 1). Of the 44 patients randomized to reldesemtiv, 41 (93.2\%) completed the 8-week study. Three patients $(6.8 \%)$, all in the $450 \mathrm{mg}$ group, discontinued treatment early due to an $\mathrm{AE}$, a protocol violation, or withdrawal by the patient; the latter 2 also withdrew from the study. Twenty-four of the 26 patients $(92.3 \%)$ in the placebo group completed the study; 2 patients $(7.7 \%)$ discontinued treatment early due to an AE but completed the planned visits for those who terminated from treatment early. One additional patient completed dosing but was lost to follow-up and did not complete the final follow-up study visit.

Baseline demographics and PD measures were generally similar across treatment groups (Table 1). The overall mean age was 29.4 years (range 12-72 years), and the majority of patients were male $(58.6 \%)$ and white $(90.0 \%)$. Most $(91.4 \%)$ patients had type III SMA (none had type IV); $44.3 \%$ were ambulatory.

\section{Outcomes}

Changes from baseline to week 8 for most of the PD parameters were not significantly different from placebo in either 
Fig. 1 Least squares mean change in outcome measures from baseline to week 8 in participants receiving reldesemtiv at doses of (A) $150 \mathrm{mg}$ bid, and (B) $450 \mathrm{mg}$ bid compared with placebo. *LSM change on reldesemtiv minus LSM change on placebo for all measures except TUG and SMA-HI, which are LSM change on placebo minus LSM change on reldesemtiv. bid = twice daily; $\mathrm{FVC}=$ forced vital capacity; HFMS-E = Hammersmith Functional Motor ScoreExpanded; LSM $=$ least squares mean; $\mathrm{MEP}=$ maximum expiratory pressure; $\mathrm{MIP}=$ maximum inspiratory pressure; $\mathrm{pbo}=$ placebo; RULM = revised upper limb module; SMA-HI = Spinal Muscular Atrophy-Health Index; TUG $=$ timed up and go
A

\% Predicted FVC
MIP
MEP
Muscle mega-score
HFMS-E
RULM
6-minute walk
Timed up and go

B

\% Predicted FVC
MIP
MEP
Muscle mega-score
HFMS-E
RULM
6-minute walk
Timed up and go
SMA-HI

reldesemtiv dose group with the exception of the 6MWT and MEP (Fig. 1).

The 6MWD increased in both the reldesemtiv 150-mg and 450-mg dose groups at weeks 4 and 8 and was fairly stable in the placebo arm (Fig. 2(A)). The LS mean difference was significantly greater than placebo at week 4 for the reldesemtiv $450 \mathrm{mg}$ bid group (35.63 m, $p=0.0037$ ); at week 8 , the difference was $24.89 \mathrm{~m}(p=0.058)$. A nominally significant LS mean difference of $30.8 \mathrm{~m}(p=0.038)$ between reldesemtiv $450 \mathrm{mg}$ bid and placebo was observed up to 4 weeks after dosing at the follow-up visit. Older age appeared to be related to larger increases in 6MWD from baseline to week $8(p=$ 0.058 ). A waterfall plot of individual changes from baseline to week 8 demonstrates that 13 of the 18 reldesemtiv-treated patients and 5 of the 9 placebo-treated patients had some improvement in 6MWD (Fig. 2(B)); of the 5 patients with the greatest improvement, 4 were on reldesemtiv.

MEP showed significant LS mean differences versus placebo for reldesemtiv $150 \mathrm{mg}$ bid $\left(11.69 \mathrm{~cm} \mathrm{H}_{2} \mathrm{O}, p=0.038\right.$, Fig. 1(A)) and for reldesemtiv $450 \mathrm{mg}$ bid $\left(13.15 \mathrm{~cm} \mathrm{H}_{2} \mathrm{O}\right.$, $p=0.03$, Fig. 1(B)). A lower baseline MEP appeared to be related to a larger increase in MEP from baseline to week 8 $(p=0.062)$. Waterfall plots of individual changes from baseline to week 8 in MEP by ambulatory status show that responses to reldesemtiv were observed in both ambulatory
Change from baseline at week 8 (150 mg bid vs. placebo) ${ }^{*}$

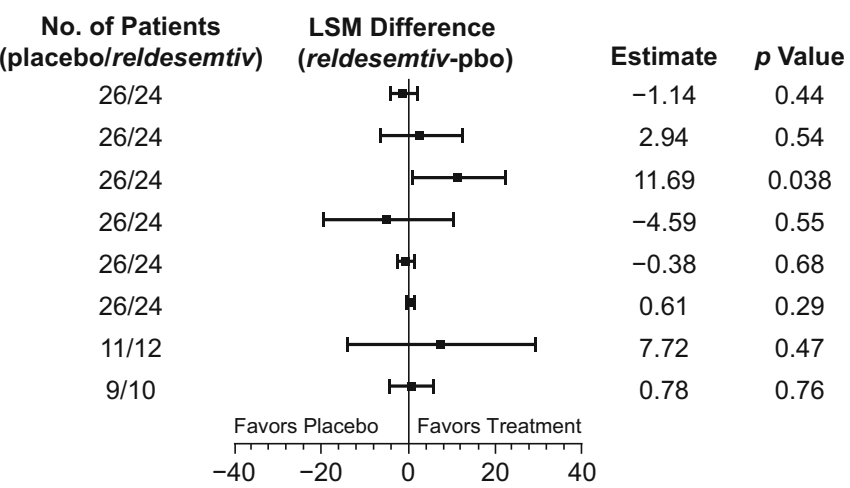

Change from baseline at week 8 (450 mg bid vs. placebo)*

\begin{tabular}{|c|c|c|c|}
\hline $\begin{array}{c}\text { No. of Patients } \\
\text { (placebo/reldesemtiv) }\end{array}$ & $\begin{array}{l}\text { LSM Difference } \\
\text { (reldesemtiv-pbo) }\end{array}$ & Estimate & $p$ Value \\
\hline $26 / 19$ & $r+1$ & -2.04 & 0.20 \\
\hline $26 / 19$ & $\longmapsto$ & -0.99 & 0.85 \\
\hline $26 / 19$ & $\longrightarrow$ & 13.15 & 0.03 \\
\hline $26 / 19$ & +1 & -15.2 & 0.067 \\
\hline $26 / 19$ & $=1$ & -1.00 & 0.31 \\
\hline $26 / 19$ & 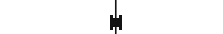 & -0.12 & 0.85 \\
\hline $11 / 7$ & & -24.89 & 0.058 \\
\hline $9 / 4$ & -1 & 3.10 & 0.35 \\
\hline $10 / 19$ & $\longmapsto$ & 0.93 & 0.83 \\
\hline Favors Placebo & Favors Tre & Favors Treatment & \\
\hline-40 & $\begin{array}{l}11 \\
-20\end{array}$ & & \\
\hline
\end{tabular}

and non-ambulatory patients (Fig. 3(A, B)). In addition, baseline values in the non-ambulatory patients were lower, whereas the ambulatory patients with higher values may have been limited by a ceiling effect.

Responses to the SMA-HI questionnaire to measure patientreported burden at 8 weeks showed no difference between the reldesemtiv $450 \mathrm{mg}$ and placebo groups ( $p=0.83$, Fig. 1(B)).

\section{Pharmacokinetics}

Plasma concentrations of reldesemtiv increased by dose (Fig. 4). Within each dose group, plasma concentrations at weeks 2 and 8 were similar. Assessment of PK parameters at week 8 showed dose-dependent increases in $C_{\max }$ and drug exposure (Table 2).

\section{Pharmacodynamic Response in Relation to Pharmacokinetics}

Individual changes from baseline to week 8 in $6 \mathrm{MWD}$ by $C_{\max }$ were examined (Fig. 5(A)). The slope of the line shows that the 6MWD increased as $C_{\max }$ increased $(p=0.0086)$. When examined by quartiles of $C_{\max }$, statistically significant and clinically meaningful changes from baseline to week 8 were observed in the highest quartile of $C_{\max }(>3.29 \mu \mathrm{g} / \mathrm{mL})$ for MEP $(p=$ $0.0002)$ and $6 \mathrm{MWD}(p=0.010)$ (Fig. 5(B)). 
Fig. 2 (A) Changes from baseline in 6MWD over time and (B) waterfall plot of individual changes from baseline to week 8 in 6MWD. 6MWD = 6-minute walking distance; bid $=$ twice daily; LSM = least squares mean; $\mathrm{m}=$ meters; $\mathrm{SEM}=$ standard error of the mean

Fig. 3 Waterfall plots of individual changes in MEP from baseline to week 8 in (A) ambulatory and (B) non-ambulatory patients. $\mathrm{MEP}=$ maximum expiratory pressure; bid = twice daily

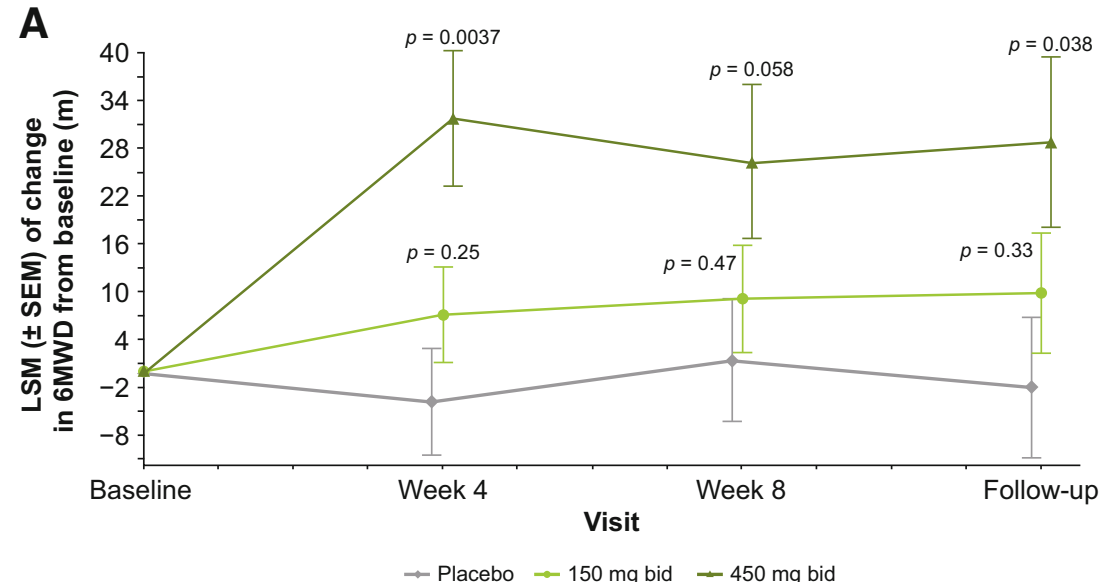

B

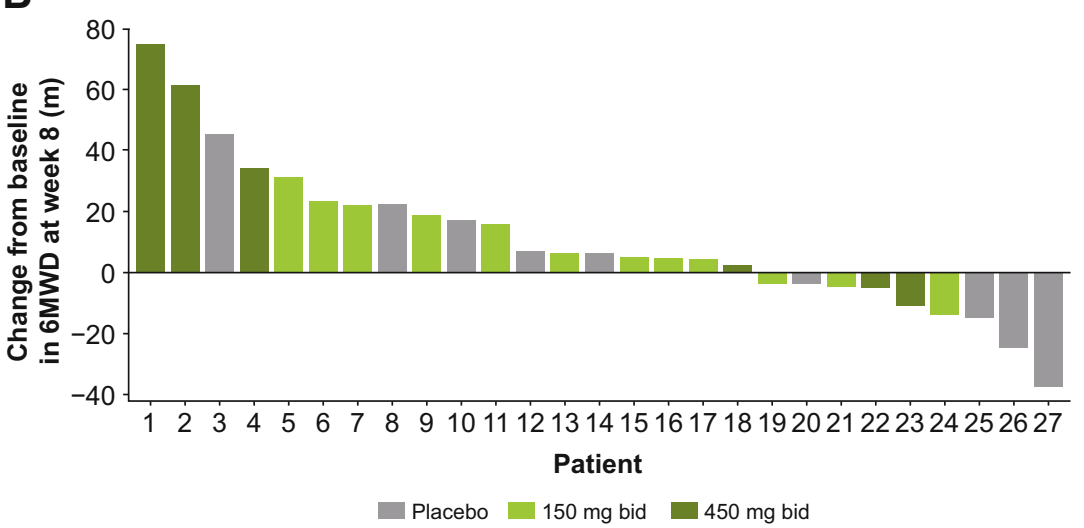

A

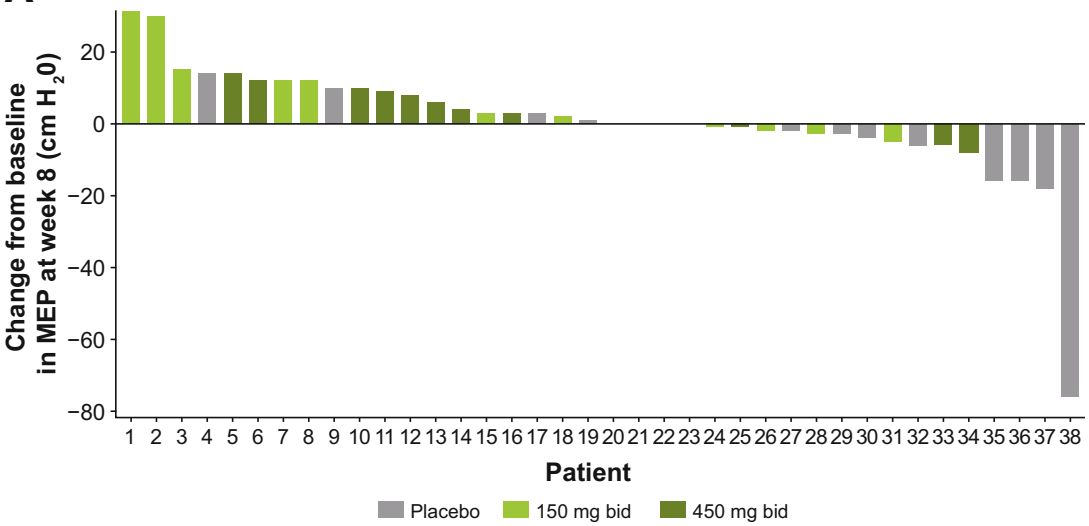

B

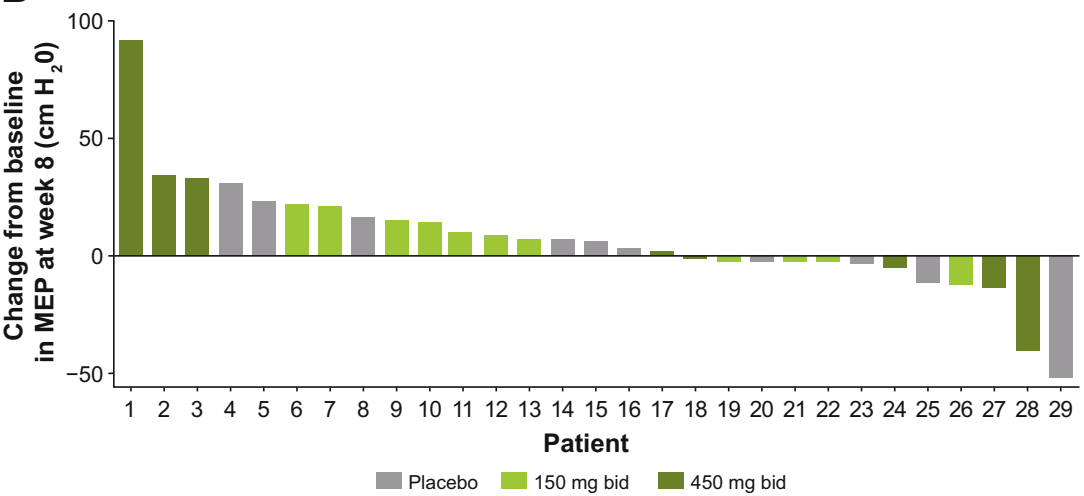


Table 2 Summary of pharmacokinetic parameters for each dose of reldesemtiv at week 8

\begin{tabular}{lll}
\hline Parameter, geometric mean (geometric \% CV) & $\begin{array}{l}\text { Reldesemtiv 150 mg bid } \\
(n=23)\end{array}$ & $\begin{array}{l}\text { Reldesemtiv 450 mg bid } \\
(n=15)^{\mathrm{a}}\end{array}$ \\
\hline$C_{\text {max }}, \mu \mathrm{g} / \mathrm{mL}$ & $1.40(43.18)$ & $3.34(48.77)$ \\
$C_{\text {trough }}, \mu \mathrm{g} / \mathrm{mL}$ & $0.34(88.27)$ & $0.94(98.06)$ \\
$\mathrm{AUC}_{0-12}, \mathrm{~h} \times \mu \mathrm{g} / \mathrm{mL}$ & $9.00(49.38)$ & $25(52.19)$ \\
\hline
\end{tabular}

${ }^{\text {a }}$ For $C_{\text {trough }}, n=17$

$A U C_{0-12}$ area under the plasma concentration curve from 0 to $12 \mathrm{~h}$, bid twice daily, $C_{\max }$ maximum observed plasma concentration, $C_{\text {trough }}$ predose plasma concentration, $C V$ coefficient of variation

\section{Safety}

AEs were reported in $92.3 \%, 83.3 \%$, and $85.0 \%$ of patients in the placebo, reldesemtiv $150 \mathrm{mg}$ bid, and reldesemtiv $450 \mathrm{mg}$ bid groups, respectively (Table 3). Most AEs were mild or moderate in severity. The most frequently reported AEs in the placebo and combined reldesemtiv groups were headache (19.2\% and $25.0 \%)$, nausea (19.2\% and $11.4 \%)$, and fatigue ( $15.4 \%$ and $9.1 \%$, respectively).

Investigator-assessed serious AEs (SAEs) were reported for 3 patients: 2 in the reldesemtiv $150 \mathrm{mg}$ bid group (gastroenteritis Escherichia coli, gastroenteritis Salmonella, and myocarditis in 1 patient and facial pain and hypesthesia for the other) and 1 in the reldesemtiv $450 \mathrm{mg}$ bid group (traumatic fracture). The sponsor also upgraded the AEs of another patient in the reldesemtiv $450 \mathrm{mg}$ bid group to SAEs (serum aspartate aminotransferase and creatine kinase increased). All SAEs resolved and none were considered to be related to the study drug. Two patients in the placebo group and 1 in the reldesemtiv $450 \mathrm{mg}$ bid group reported AEs that led to early treatment termination (Table 3); all were considered by the treating investigator to be related to the study drug. No deaths were reported during the study.

\section{Discussion}

In this hypothesis-generating study, 6MWD and MEP improved versus placebo in patients with SMA receiving reldesemtiv, consistent with increased skeletal muscle force production by reldesemtiv. The LS mean change from baseline in the 6MWD at week 4 was significantly greater for reldesemtiv $450 \mathrm{mg}$ bid compared with placebo, and difference at week 8 trended to conventional statistical significance. There was a persistent effect in the 6MWD 4 weeks after the last dose; a similar persistent benefit in slow vital capacity was also observed in the FORTITUDE-ALS phase 2 trial of reldesemtiv in amyotrophic lateral sclerosis (ALS) patients [24], and in a phase 2 ALS trial with tirasemtiv, a first-generation fast skeletal muscle activator [25]. MEP measurements, which reflect expiratory muscle strength, demonstrated a nominal increase at week 8 for both reldesemtiv treatment groups compared with placebo. Changes seen in MEP but not in FVC may be related to the well-known relative preservation of the diaphragm compared to other ventilatory muscles in SMA [26]. Significant changes from placebo at week 8 were seen in 6MWD and MEP in the highest quartiles of $C_{\max }$ for reldesemtiv. These results are consistent with those from phase 1 studies of reldesemtiv in healthy volunteers in which significant dose- and frequency-dependent increases were observed in the peak force of tibialis anterior muscle contraction after deep fibular nerve stimulation following treatment with reldesemtiv [18].

As adult SMA patients have historically not been included in most interventional SMA trials, this trial offers insights into the challenges encountered with the commonly used SMA outcome measures in this older patient population. Because reldesemtiv is known to increase skeletal muscle force in response to neural input, outcome measures specific to fatigue and muscle force may be more sensitive to changes due to treatment. The HFMSE
Fig. 4 Plasma concentrations of reldesemtiv over time. Error bars represent standard errors. bid $=$ twice daily

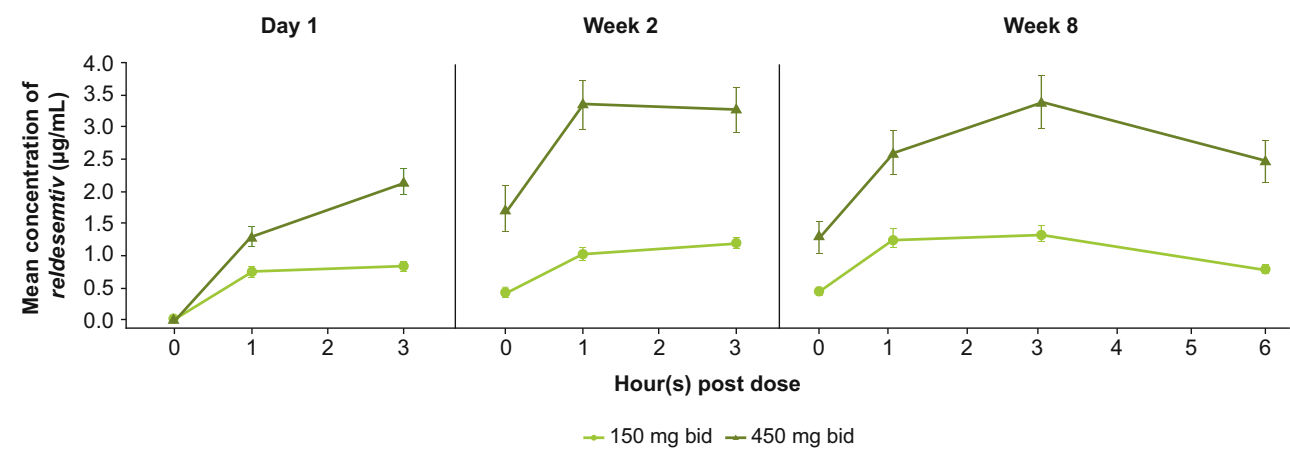


Fig. 5 (A) Individual changes from baseline to week 8 in 6MWD by $C_{\max }$, and (B) changes from baseline to week 8 in MEP and 6MWD by quartiles of $C_{\max }$. *Difference between placebo and reldesemtiv. $6 \mathrm{MWD}=6$-minute walking distance; $\mathrm{C}_{\max }=$ maximum observed plasma concentration; LSM = least squares mean; $\mathrm{MEP}=$ maximum expiratory pressure; pbo $=$ placebo
A

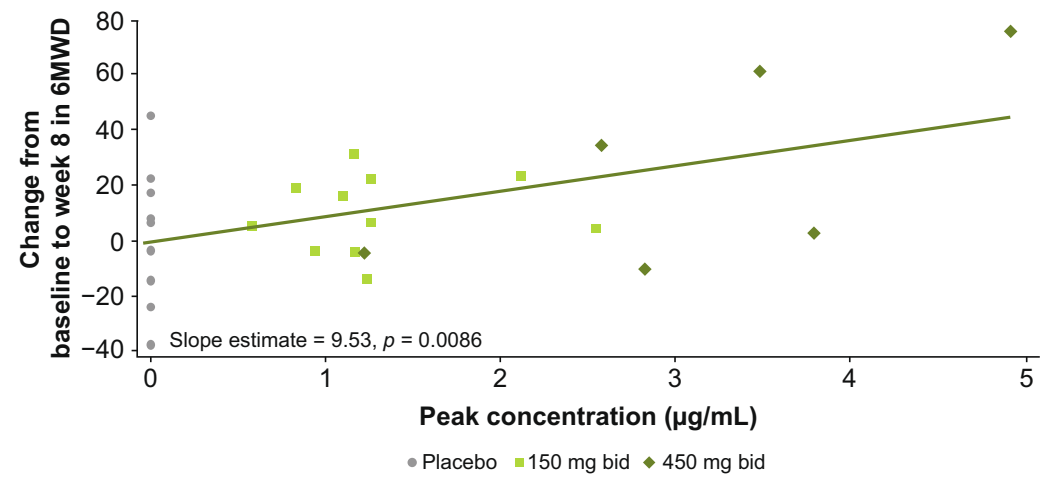

B

Change from baseline at week 8

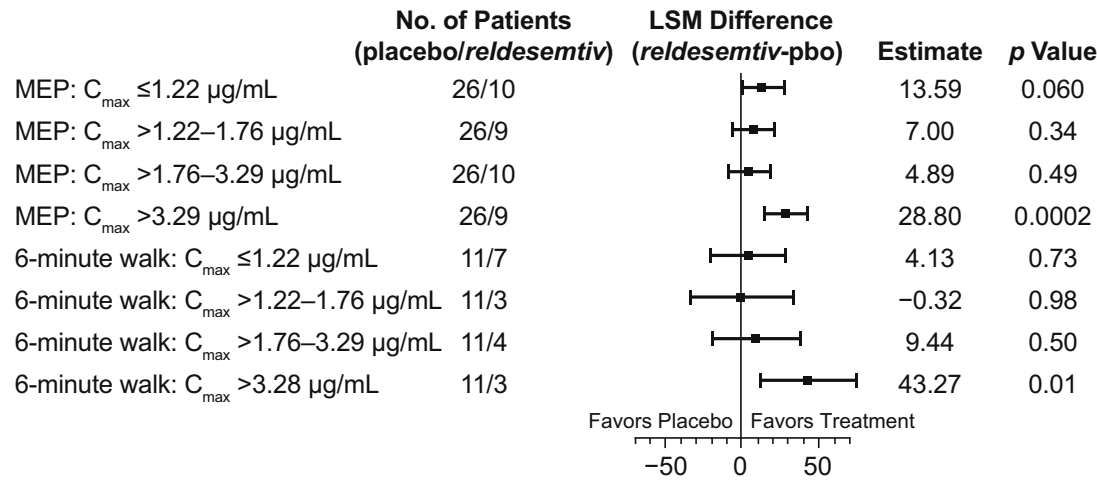

was developed for children with SMA, and includes crawling and arising from the floor, which are infrequently performed by adults, resulting in their assessment being impacted by a motor learning effect in addition to weakness from SMA. The HFMSE also includes no timed tests, so is insensitive to changes in stamina or fatigue. More sensitive outcome measures are needed to address these domains that have been reported as important to the adult SMA patient population. Potential alternatives to the HFMSE include the Revised Hammersmith (RHS) and Motor Function Measurement 32 (MFM-32) assessments. The RHS includes 2 timed tests, though it still includes crawling and kneeling. Testing has been done in the RHS for a small number of patients over the age of 14 [27]. The MFM-32 was developed for use in patients aged 6 to 60 years and does not require the patient to kneel or crawl. It has the additional benefit of having the items classified into 3 domains: D1 for standing and transfers, D2 for axial and proximal motor function and D3 for distal motor function. In an ambulatory patient population, D1 items are likely to be most impacted, whereas D2 may or may not be abnormal depending on the degree of their limb and trunk weakness. This permits response to an intervention to be measured both for the overall
MFM-32 score as well as the scores of the individual domains [28-30].

The SMA-HI questionnaire was used to assess patientreported disease burden as an exploratory outcome. No difference was observed between reldesemtiv and placebo treatment groups at week 8 . The SMA-HI was added to the protocol for the second cohort only. Because some sites were delayed in getting approval for the revised protocol and consent form, only 19 patients filled out the SMA-HI, limiting the ability to draw meaningful conclusions from this initial investigation, though a patient-reported outcome measure will clearly be of value for treatment of unmet needs in this patient population.

PK exposures in this study were below levels that were well tolerated and associated with increased PD activity compared to placebo in the phase 1 studies (that used a different drug formulation). The reldesemtiv dose levels tested here, $150 \mathrm{mg}$ and $450 \mathrm{mg}$ administered twice daily, were also well tolerated and associated with increased PD activity compared with placebo treatment. The AEs reported were generally similar to those in the placebo group and were consistent with those observed in phase 1 studies of reldesemtiv [18]. The good tolerability of these dose levels, as well as no evidence of an efficacy plateau in this trial, and the prior safety and tolerability of higher exposures that generated even larger 
Table 3 Adverse events reported in $\geq 2$ patients treated with reldesemtiv

\begin{tabular}{|c|c|c|c|c|}
\hline Preferred term ${ }^{\mathrm{a}}, n(\%)$ & $\begin{array}{l}\text { Placebo } \\
(n=26)\end{array}$ & $\begin{array}{l}\text { Reldesemtiv } \\
150 \mathrm{mg} \text { bid } \\
(n=24)\end{array}$ & $\begin{array}{l}\text { Reldesemtiv } \\
450 \mathrm{mg} \text { bid } \\
(n=20)\end{array}$ & $\begin{array}{l}\text { All } \\
\text { reldesemtiv } \\
(n=44)\end{array}$ \\
\hline Patients with AEs & $\begin{array}{l}24 \\
\quad(92 .- \\
\text { 3) }\end{array}$ & $20(83.3)$ & $17(85.0)$ & $37(84.1)$ \\
\hline Headache & $5(19.2)$ & $6(25.0)$ & $5(25.0)$ & $11(25.0)$ \\
\hline Nausea & $5(19.2)$ & $3(12.5)$ & $2(10.0)$ & $5(11.4)$ \\
\hline Fatigue & $4(15.4)$ & $2(8.3)$ & $2(10.0)$ & $4(9.1)$ \\
\hline Fall & $3(11.5)$ & $1(4.2)$ & $1(5.0)$ & $2(4.5)$ \\
\hline Nasopharyngitis & $3(11.5)$ & $3(12.5)$ & 0 & $3(6.8)$ \\
\hline Upper respiratory tract infection & $4(15.4)$ & 0 & $2(10.0)$ & $2(4.5)$ \\
\hline Constipation & 0 & $3(12.5)$ & $2(10.0)$ & $5(11.4)$ \\
\hline Diarrhea & $2(7.7)$ & $2(8.3)$ & $1(5.0)$ & $3(6.8)$ \\
\hline Abdominal pain upper & $1(3.8)$ & $2(8.3)$ & 0 & $2(4.5)$ \\
\hline Dyspepsia & 0 & $2(8.3)$ & $1(5.0)$ & $3(6.8)$ \\
\hline Contusion & 0 & $2(8.3)$ & 0 & $2(4.5)$ \\
\hline Respiratory tract congestion & 0 & $2(8.3)$ & 0 & $2(4.5)$ \\
\hline Serum creatine kinase increased & 0 & 0 & $2(10.0)$ & $2(4.5)$ \\
\hline Skin abrasion & 0 & 0 & $2(10.0)$ & $2(4.5)$ \\
\hline Decreased appetite & $1(3.8)$ & $1(4.2)$ & $1(5.0)$ & $2(4.5)$ \\
\hline Hypoesthesia & 0 & $1(4.2)$ & $1(5.0)$ & $2(4.5)$ \\
\hline Respiratory tract infection & 0 & $1(4.2)$ & $1(5.0)$ & $2(4.5)$ \\
\hline $\begin{array}{l}\text { Patients with AEs resulting in early } \\
\text { treatment termination }\end{array}$ & $2(7.7)$ & 0 & $1(5.0)$ & $1(2.3)$ \\
\hline Serum creatine kinase increased & 0 & 0 & $1(5.0)$ & $1(2.3)$ \\
\hline Asthenia & $1(3.9)$ & 0 & 0 & 0 \\
\hline Gait disturbance & $1(3.9)$ & 0 & 0 & 0 \\
\hline Muscular weakness & $1(3.9)$ & 0 & 0 & 0 \\
\hline
\end{tabular}

${ }^{\text {a }}$ Medical Dictionary for Regulatory Activities (version 18.0)

$A E$ adverse event
PD effects in the PD study provide a rationale to study higher dose levels in an effort to increase exposures.

The small population size and relatively short treatment period are limitations of this study. In addition, the results for MEP at 8 weeks were nominally statistically significant for both doses of reldesemtiv compared to placebo; for the $6 \mathrm{MWD}$, only the higher dose of reldesemtiv was nominally statistically significant compared to placebo at 4 weeks and trended towards significance at 8 weeks. In a post hoc analysis of baseline features, a trend to predicting a response in MEP was limited to a lower baseline MEP value and only older age showed a trend to predicting a response in the 6MWD.

However, the purpose of this trial was to generate hypotheses to test in future studies and so it had no predetermined clinical primary endpoint. Good tolerability and the observation that 6MWD and MEP increased with plasma concentrations support future studies of reldesemtiv in larger populations of individuals with SMA. As reldesemtiv has a distinctly different mechanism of action compared to currently available therapies for SMA that increase levels of the SMN protein, in a future reldesemtiv trial, we anticipate including eligibility criteria permitting current or past use of such medicines with enrolled patients stratified accordingly. In conclusion, we believe the promising effects of reldesemtiv on 6MWD and MEP, in association with tolerability of the doses employed in this trial, support further clinical development of reldesemtiv for the potential treatment of patients with SMA.

Supplementary Information The online version contains supplementary material available at https://doi.org/10.1007/s13311-020-01004-3.

Acknowledgments The study was conducted by Cytokinetics, Incorporated, South San Francisco, CA, USA, and funded by Astellas Pharma Inc., Tokyo, Japan, as part of the collaboration between Cytokinetics and Astellas. The authors are grateful to the patients and the SMA community for help in the successful completion of this trial. The authors would like to thank Dr. John Brandsema, Dr. Thomas Crawford, Dr. Stacy Dixon, Dr. Richard Finkel, Dr. John Kissel, Dr. Julie Parsons, Dr. Kathryn Selby, and Dr. Edward Smith for their contributions to the study. Cytokinetics, Incorported provided funding for 
writing and editorial support provided by Jennifer L. Giel, $\mathrm{PhD}$ on behalf of Evidence Scientific Solutions, Inc., Philadelphia, PA, USA.

Required Author Forms

Disclosure forms provided by the authors are available with the online version of this article.

Open Access This article is licensed under a Creative Commons Attribution 4.0 International License, which permits use, sharing, adaptation, distribution and reproduction in any medium or format, as long as you give appropriate credit to the original author(s) and the source, provide a link to the Creative Commons licence, and indicate if changes were made. The images or other third party material in this article are included in the article's Creative Commons licence, unless indicated otherwise in a credit line to the material. If material is not included in the article's Creative Commons licence and your intended use is not permitted by statutory regulation or exceeds the permitted use, you will need to obtain permission directly from the copyright holder. To view a copy of this licence, visit http://creativecommons.org/licenses/by/4.0/.

\section{References}

1. Kolb SJ, Kissel JT. Spinal muscular atrophy. Neurol Clin 2015;33: 831-846.

2. Stevens L, Bastide B, Maurage CA, et al. Childhood spinal muscular atrophy induces alterations in contractile and regulatory protein isoform expressions. Neuropathol Appl Neurobiol 2008;34: 659-670.

3. Martínez-Hernández R, Bernal S, Alias L, Tizzano EF. Abnormalities in early markers of muscle involvement support a delay in myogenesis in spinal muscular atrophy. J Neuropathol Exp Neurol 2014;73:559-567.

4. Brogna C, Cristiano L, Verdolotti T, et al. MRI patterns of muscle involvement in type 2 and 3 spinal muscular atrophy patients. J Neurol 2020;267:898-912.

5. Finkel RS, Mercuri E, Darras BT, et al. Nusinersen versus sham control in infantile-onset spinal muscular atrophy. N Engl J Med 2017;377:1723-1732.

6. Mercuri E, Darras BT, Chiriboga CA, et al. Nusinersen versus sham control in later-onset spinal muscular atrophy. N Engl J Med 2018;378:625-635.

7. Gidaro T, Servais L. Nusinersen treatment of spinal muscular atrophy: current knowledge and existing gaps. Dev Med Child Neurol 2019;61:19-24.

8. Darras BT, Chiriboga CA, Iannaccone ST, et al. Nusinersen in later-onset spinal muscular atrophy: long-term results from the phase 1/2 studies. Neurology 2019;92:e2492-e2506.

9. Walter MC, Wenninger S, Thiele S, et al. Safety and treatment effects of nusinersen in longstanding adult 5q-SMA type 3 - a prospective observational study. J Neuromuscul Dis 2019;6:453465.

10. Hagenacker T, Wurster CD, Günther R, et al. Nusinersen in adults with $5 \mathrm{q}$ spinal muscular atrophy: a non-interventional, multicentre, observational cohort study. Lancet Neurol 2020;19:317-325.

11. ZOLGENSMA ${ }^{\circledR}$. (onasemnogene abeparvovec-xioi) suspension for intravenous infusion. U.S. Bannockburn, IL; AveXis, Inc.; 2019.

12. Mendell JR, Al-Zaidy S, Shell R, et al. Single-dose gene-replacement therapy for spinal muscular atrophy. N Engl J Med 2017;377: $1713-1722$.
13. EVRYSDI ${ }^{\mathrm{TM}}$. (risdiplam) for oral solution. U.S. South San Francisco, CA; Genentech Inc.; 2020.

14. Mercuri E, Barisic N, Boespflug-Tanguy O, et al. SUNFISH Part 2: efficacy and safety of risdiplam (RG7916) in patients with type 2 or non-ambulant type 3 spinal muscular atrophy (SMA) (1260). Neurology 2020;94:1260.

15. Swoboda KJ, Prior TW, Scott CB , et al. Natural history of denervation in SMA: relation to age, SMN2 copy number, and function. Ann Neurol 2005;57:704-712.

16. Talbot K, Tizzano EF. The clinical landscape for SMA in a new therapeutic era. Gene Ther 2017;24:529-533.

17. Hwee DT, Kennedy AR, Hartman JJ, et al. The small-molecule fast skeletal troponin activator, CK-2127107, improves exercise tolerance in a rat model of heart failure. J Pharmacol Exp Ther 2015;353:159-168.

18. Andrews JA, Miller TM, Vijayakumar V, et al. CK-2127107 amplifies skeletal muscle response to nerve activation in humans. Muscle Nerve 2018;57:729-734.

19. O'Hagen JM, Glanzman AM, McDermott MP, et al. An expanded version of the Hammersmith Functional Motor Scale for SMA II and III patients. Neuromuscul Disord 2007;17:693-697.

20. Mazzone ES, Mayhew A, Montes J, et al. Revised upper limb module for spinal muscular atrophy: development of a new module. Muscle Nerve 2017;55:869-874.

21. Dunaway Young S, Montes J, Kramer SS, et al. Six-minute walk test is reliable and valid in spinal muscular atrophy. Muscle Nerve 2016;54:836-842.

22. Dunaway S, Montes J, Garber CE, et al. Performance of the timed "up \& go" test in spinal muscular atrophy. Muscle Nerve 2014;50: 273-277.

23. Mongiovi P, Dilek N, Garland C, et al. Patient Reported Impact of Symptoms in Spinal Muscular Atrophy (PRISM-SMA). Neurology 2018;91:e1206-e1214.

24. Shefner J, Andrews J, Genge A, et al. Update of FORTITUDEALS: a phase 2, double-blind, randomized, placebo-controlled, study to evaluate efficacy, safety and tolerability of reldesemtiv in patients with amyotrophic lateral sclerosis (S5.002). Neurology 2019;92:S5.002.

25. Shefner JM, Wolff AA, Meng L, et al. A randomized, placebocontrolled, double-blind phase IIb trial evaluating the safety and efficacy of tirasemtiv in patients with amyotrophic lateral sclerosis. Amyotroph Lateral Scler Frontotemporal Degener 2016;17:426435.

26. Arnold WD, Kassar D, Kissel JT. Spinal muscular atrophy: diagnosis and management in a new therapeutic era. Muscle Nerve 2015;51:157-167.

27. Ramsey D, Scoto M, Mayhew A, et al. Revised Hammersmith Scale for spinal muscular atrophy: a SMA specific clinical outcome assessment tool. PLoS One 2017;12:e172346.

28. Bérard C, Payan C, Hodgkinson I, Fermanian J, MFM Collaborative Study Group. A motor function measure for neuromuscular diseases. Construction and validation study. Neuromuscul Disord 2005;15:463-470.

29. Vuillerot C, Payan C, Iwaz J, Ecochard R, Bérard C, MFM Spinal Muscular Atrophy Study Group. Responsiveness of the motor function measure in patients with spinal muscular atrophy. Arch Phys Med Rehabil 2013;94:1555-1561.

30. Chabanon A, Seferian AM, Daron A, et al. Prospective and longitudinal natural history study of patients with type 2 and 3 spinal muscular atrophy: baseline data NatHis-SMA study. PLoS One 2018;13:e201004.

Publisher's Note Springer Nature remains neutral with regard to jurisdictional claims in published maps and institutional affiliations. 